\title{
Importância do mapeamento geomorfológico como subsídio aos estudos sobre desertificação
}

\author{
Importance of geomorphological mapping as subsidy to studies of desertification
}

ROCHA ${ }^{1}$, Dyego Freitas; SOUZA ${ }^{2}$, Henrique Clementino de.

dyegofreitasrocha@gmail.com;

\begin{abstract}
Resumo
O presente artigo tem como objetivo discutir brevemente algumas técnicas de mapeamento geomorfológico elaboradas por alguns autores, entre eles: ROSS (1992), AB'SABER (1969) e IBGE (2009). Através da revisão de literatura, analisando a importância do mapeamento geomorfológico como ferramenta de análise para os estudos sobre a desertificação. Além disso, são apresentados o uso das geotecnologias para o mapeamento geomorfológico, seja por meio dos Modelos Digitais do Terreno (MDTs) e seus subprodutos: mapas de Declividade, Relevo Sombreado e Mapas hipsométricos ou pelos Sistemas de Informação Geográfica. Diante do conteúdo apresentado, são discutidos alguns estudos selecionados que tratam do uso de mapeamento geomorfológico aplicado aos estudos sobre desertificação, detalhando sucintamente as investigações executadas pelos seguintes autores: AQUINO (2010), SANTOS (2015), LIMA et. al. (2011), OLIVEIRA e CHAVES (2010) e NASCIMENTO (2006). Palavras-chave: Geomorfologia; Mapeamento Geomorfológico; Desertificação.
\end{abstract}

\begin{abstract}
This article aims to briefly discuss some geomorphological mapping techniques developed by some authors, including: ROSS (1992), AB'SABER (1969) and IBGE (2009). Through literature review, analyzing the importance of geomorphological mapping and analysis tool for studies on desertification. In addition, they present the use of geotechnology for geomorphological mapping, either by means of Digital Terrain Models (DTMs) and its by-products: declivity maps, Shaded Relief and hypsometric maps or by Geographic Information Systems. Before the content presented, they are discussed some selected studies that address the use of geomorphological mapping applied to studies on desertification, briefly detailing the investigations carried out by the following authors: AQUINO (2010), SANTOS (2015), LIMA et. al. (2011), OLIVEIRA e CHAVES (2010) and NASCIMENTO (2006).
\end{abstract}

Keywords: Geomorphology; Geomorphological Mapping. Desertification

\section{INTRODUÇÃO}

A geomorfologia é um importante componente da Geografia, possuindo grande relevância na análise dos fenômenos ambientais e servindo de subsídio para a elaboração de vários estudos do meio físico. Em relação às geociências, a geomorfologia é uma importante área do conhecimento que subsidia a caracterização do ambiente, propondo a análise e a compreensão das formas de relevo através dos processos nelas existentes e a compreensão dos processos morfogenéticos.

Para Casseti (2006), no momento em que se faz uma análise do relevo atual e as formas que por ele são apresentadas, os fatores externos não são considerados em primeiro plano, considerando que estão inseridos na escala de tempo geológico. Existindo uma exceção para áreas que são afetadas por eventos de grandes proporções, como os vulcanismos e abalos sísmicos, que evidenciam áreas de dobramentos modernos. No pensamento de Penteado (1980), as formas de 
relevo representam entidades dinâmicas que evoluem em detrimento das acomodações que são inerentes a cada processo atuante na superfície terrestre.

Para Christofoletti (1973 apud SILVA, 2016), as formas de relevo representam a expressão espacial e uma superfície, composta pelas diversas configurações da paisagem geomorfológica. O autor ainda reitera que as formas foram esculpidas pela ação de processos específicos.

Para Florenzano (2008), dependendo de suas características, o relevo favorece ou dificulta a ocupação dos ambientes terrestres pelo homem, pois a superfície terrestre não é plana nem uniforme em toda a sua extensão. Ao contrário, caracteriza-se por elevações e depressões de diferentes formas com maior ou menor grau de acentuação (horizontais ou tabulares, convexas, côncavas, angulares e escarpadas) que constituem seu relevo.

Segundo Oliveira (2010, p. 218):

A geomorfologia insere-se como componente da ciência geográfica com uma contribuição potencial no que se refere à elucidação de fenômenos ambientais, no subsídio ao desenvolvimento desses estudos e, consequentemente com uma compreensão integrada da paisagem.

Dessa maneira, os estudos sobre a desertificação são desenvolvidos com respaldo às abordagens da geomorfologia. O termo desertificação de acordo com a Convenção das Nações Unidas de Combate à Desertificação (ONU, 1977 apud LIMA et. al., 2012, p. 589) é dado pela “degradação da terra nas regiões áridas, semiáridas e sub-úmidas secas, resultante de vários fatores, entre eles, variações climáticas e atividades humanas".

Nesse âmbito, o presente trabalho visa realizar uma breve discussão dos aspectos teóricosmetodológicos que servem de aporte para a realização do mapeamento geomorfológico, além de uma breve caracterização das abordagens dos estudos geomorfológicos e apresentação de alguns estudos que retratam a temática da desertificação, que está se tornando bastante evidente no atual cenário das questões ambientais.

\section{METODOLOGIA}

Como metodologia foram realizadas leituras e análises de algumas referências selecionadas, bem como revisão de literatura, sejam de livros, dissertações, teses ou artigos científicos publicados em periódicos e/ou eventos acadêmicos de modo a utilizá-los como ferramentas de análise do estado da arte do mapeamento geomorfológico para os estudos sobre a desertificação.

\section{RESULTADOS E DISCUSSÃO}


O mapeamento geomorfológico é um instrumento de grande significância, no que cerne a espacialização dos fenômenos geomorfológicos, propiciando a representação espacial da gênese das formas de relevo, além de suas estruturas e processos, levando em conta as suas peculiaridades.

Em questões de escala de análise, a escala de detalhe, é evidente a ação dos diversos climas em relação às litologias variadas, o que acarreta na existência de formas de relevo características a cada tipo de ambiente, como as formações tabulares, convexas e aguçadas. Nesse contexto, cada característica das formas de relevo pode ser definida pelas diferenças litológicas e estruturais a partir da ação dos domínios morfoclimáticos que irão atuar no substrato geológico e na quantidade de energia para que haja o trabalho geomorfológico (CASSETI, 2006).

De acordo com Silva (2007, p.7), as escalas de representação cartográfica possuem apropriação a cada objetivo para determinados estudos: a) estudos voltados ao manejo ambiental (escalas de 1:2.000 a 1:10.000); b) planejamento urbano e/ou regional (escalas de 1:10.000 a 1:50.000); c) elaboração de inventários e levantamentos de recursos naturais (escalas de 1:25.000 a 1:100.000) e d) escalas acima de 1:100.000 são caracterizadas por um reconhecimento de pesquisa regional.

Analiticamente, os processos decorrentes nas mais diversas escalas representam a integração dos mais variados elementos ambientais, sendo necessário o trabalho de campo para análise, identificação e descrição, remontando aos preceitos de coleta de dados com abordagem empírica (SILVA, 2007).

Nessa perspectiva, a cartografia geomorfológica se faz um importante elemento para a análise e representação dos fenômenos geomorfológicos. Para Ab'Saber (1969 apud SCHINEIDER, 2011) a cartografação da paisagem é sistematizada em três níveis distintos para o avanço da pesquisa geomorfológica. $\mathrm{O}$ primeiro nível está relacionado com a compartimentação geomorfológica no que tange a caracterização e descrição das formas de relevo; o segundo nível refere-se ao levantamento da estrutura das superfícies das paisagens e o terceiro nível é referente ao estudo fisiologia da paisagem, no entendimento dos processos morfoclimáticos e pedogenéticos modernos.

Desse modo, Ross (1992) também apresenta a metodologia de análise do relevo através da divisão taxonômica, a partir da abordagem tridimensional: $1^{\mathrm{o}}$ Táxon: Morfoestrutura, $2^{\circ}$ Táxon: Morforescultura, $3^{\circ}$ Táxon: Unidades Morfológicas, $4^{\circ}$ Táxon: Formas de Relevo, $5^{\circ}$ Táxon: Tipos de Vertentes e $6^{\circ}$ Táxon: Pequenas formas desenvolvidas na atualidade.

Segundo Ross (1991), a morfoestrutura está relacionada com as zonas de grandes extensões superficiais, onde são identificadas as áreas de Escudos Antigos ou as Bacias Sedimentares. E 
nestas áreas são encontradas as características morfoesculturais, definidas pelos compartimentos gerados pela ação do clima em escala de tempo geológico.

O terceiro táxon ou as unidades morfológicas, são referentes às manchas de formas com fisionomia semelhante, classificadas pela rugosidade topográfica ou pela dissecação do relevo. São diferenciadas de acordo com a natureza genética: formas agradacionais, formas de acumulação, formas denudacionais ou formas de erosão.

Neste táxon, são adotadas algumas codificações para os ambientes de denudação e acumulação, de acordo com RADAMBRASIL - MME/DNPM, 1982 apud ROSS (1996):

Quadro 1: Formas de Relevo

\begin{tabular}{|c|c|}
\hline FORMAS DENUDACIONAIS & FORMAS AGRADACIONAIS \\
\hline $\mathrm{D}$ - denudação & $\mathrm{A}-$ acumulação \\
\hline $\mathrm{Da}$ - formas de topos aguçados & Apf - formas de planície fluvial \\
\hline Dc - formas de topos convexos & Apm - formas de planície marinha \\
\hline $\mathrm{Dt}$ - formas de topos tabulares & Apl - formas de planície lacustre \\
\hline $\mathrm{Dp}$ - formas de superfícies planas & Api - formas de planície intertidal \\
\hline De - formas de escarpas & Ad - formas de campos de dunas \\
\hline $\mathrm{Dr}$ - formas de rampas & Atf - formas de terraços fluviais \\
\hline & Atm - formas de terraços marinhos \\
\hline
\end{tabular}

Fonte: Adaptado de Ross (1996).

O táxon das formas de relevo é relativo às formas de relevos que estão contidas nas unidades morfológicas ou de padrões de formas semelhantes, quando analisadas em escala de detalhe, apresentam características fisionômicas pertinentes a cada forma (ROSS, 1991).

O Manual técnico de Geomorfologia do Instituto Brasileiro de Geografia e Estatística (IBGE, 2009), se apresenta como um tutorial inicial para as pesquisas voltadas ao mapeamento geomorfológico no Brasil. O manuscrito tem como fator organizacional o ordenamento dos fatos geomorfológicos com classificação temporal-espacial, na qual são diferenciados as unidades básicas e seus grupamentos hierarquicamente relacionados (IBGE, 2009, p. 27), conforme figura abaixo:

Figura 1: Etapas do mapeamento geomorfológico 


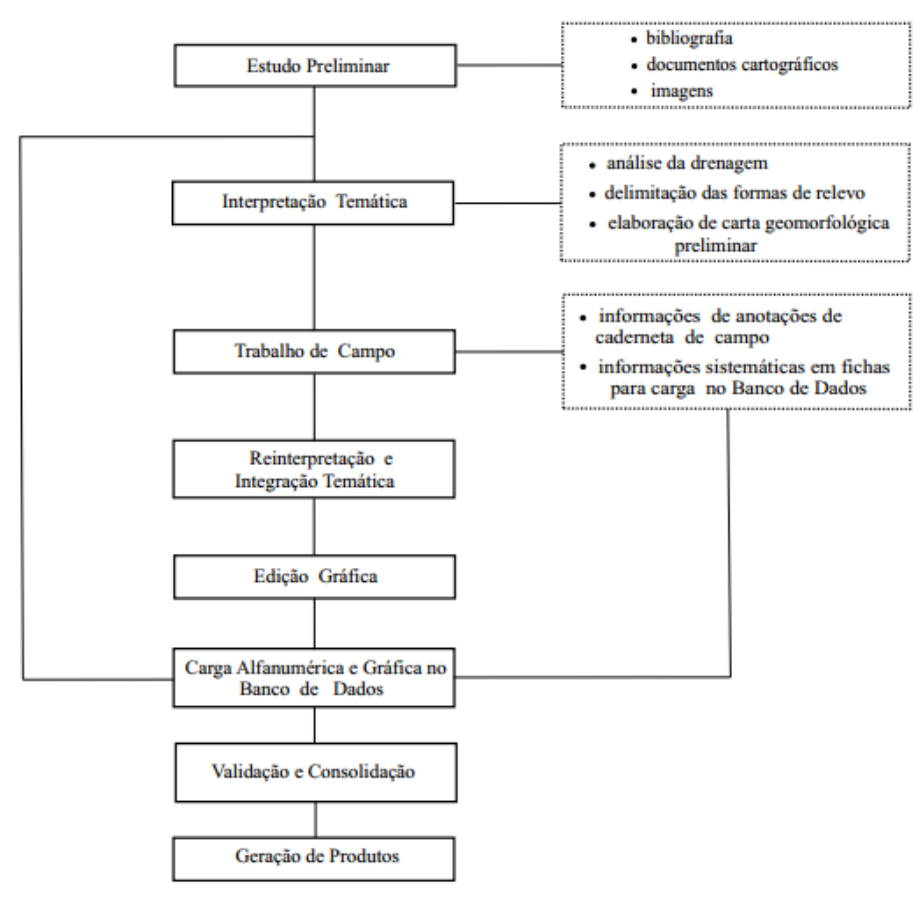

Fonte: Adaptado de IBGE (2009).

Em termos, para Tricart (1965 apud AUGUSTIN et. al., 2011, p. 51):

Os mapeamentos geomorfológicos abordam quatro tipos principais de representação: a da morfometria, correspondendo à altimetria, dimensões, desníveis, extensões entre outros itens associados à mensuração das unidades do relevo, a da morfologia, agregada à forma das vertentes, vales e topos, a da gênese ligada à desnudação e/ou agradação e à cronologia (idade relativa e datação absoluta das formas) e a do comportamento morfodinâmico.

$\mathrm{O}$ avanço das tecnologias e, por conseguinte, dos softwares de processamento de dados georreferenciados, os Sistemas de Informação Geográfica (SIG) e de sensoriamento remoto, contribuem sensivelmente para os estudos ambientais, especialmente os estudos relacionados à análise das estruturas e formas de relevo, permitindo a geração de produtos de qualidade e mais próximos à realidade das áreas estudadas. A partir dos SIGs, são criadas representações da superfície terrestre em modelos digitais, referentes a matrizes formadas por linhas e colunas contendo os atributos de altimetria ou pontos de cotas altimétricas do terreno, conhecidos como Modelos Digitais do Terreno (MDT), ou em inglês Digital Terrain Model.

Os MDTs são definidos como uma representação matemática da espacialização das cotas altimétricas na superfície do planeta, seja em determinadas áreas de estudo ou em regiões específicas. Desse modo, os MDTs possibilitam os estudos dos fenômenos ocorrentes em determinadas áreas, através do cálculo de volumes, de áreas, perfis topográficos e seções transversais, geração de relevos sombreados, mapas de declividade e exposição de vertentes, além de perspectivas em três dimensões (ROCHA, 2011). 
Os Modelos Digitais do Terreno, geralmente são baseados em dados obtidos a partir do projeto Shuttle Radar Topography Mission (SRTM) da NASA. Os MDTs são modelos de representação espacial, formado por grades digitais de pixels que são baseados na altimetria de determinadas áreas, conhecido como o atributo Z. Nos modelos gerados pelo SRTM, as imagens possuem resolução espacial de $90 \mathrm{~m}$ para 3 arcos de segundo, isto é, cada pixel possui resolução de 90 m. Nas atualizações recentes do projeto SRTM, são disponibilizadas imagens com resolução espacial de 30 m, de melhor qualidade. Segundo Schineider (2011), também há outra opção de MDT, o projeto Aster Global DEM, elaborado em conjunto pela NASA e o governo japonês, desde 2009, através das imagens obtidas pelo satélite ASTER, que também possui resolução espacial de $30 \mathrm{~m}$.

Em termos conceituais os Modelos Digitais do Terreno, são representações matemáticas da espacialização das cotas altimétricas de determinada área de estudo. São gerados a partir do método de interpolação das curvas de nível ou de pontos topográficos de referência, desse modo, a interpolação dos dados coletados é realizada através dos softwares SIG (ROCHA, 2011).

Os modelos são criados através de amostragens dos fenômenos nas áreas de interesse para determinados estudos, ocorrendo o processamento das formas de modo a gerar os modelos digitais que representam de forma computacional o fenômeno estudado.

De acordo com Felgueiras, 2009 (apud ROCHA, 2011, p. 20): Os modelos digitais são utilizados por uma série de procedimentos de análises úteis para aplicação em geoprocessamento.

Dessa maneira, utilizando as técnicas de geoprocessamento o mapeamento geomorfológico serve de base para sintetizar todas as variáveis existentes no meio físico, indicando os pontos de fragilidade e potencialidade do ambiente, considerando as relações dos mais diversos componentes (geologia, solos, cobertura vegetal, clima e ação antrópica), na paisagem (ROSS, 1990 apud OLIVEIRA 2010).

A partir do Modelo Digital do Terreno (MDT), podem ser gerados outros produtos como o mapa de hipsometria, mapa de declividade, mapa de sombreamento, mapa de aspecto (vertentes) e mapa de curvatura horizontal e vertical, de acordo com o fluxograma abaixo.

Figura 2: Fluxograma de geração de Mapas Temáticos 


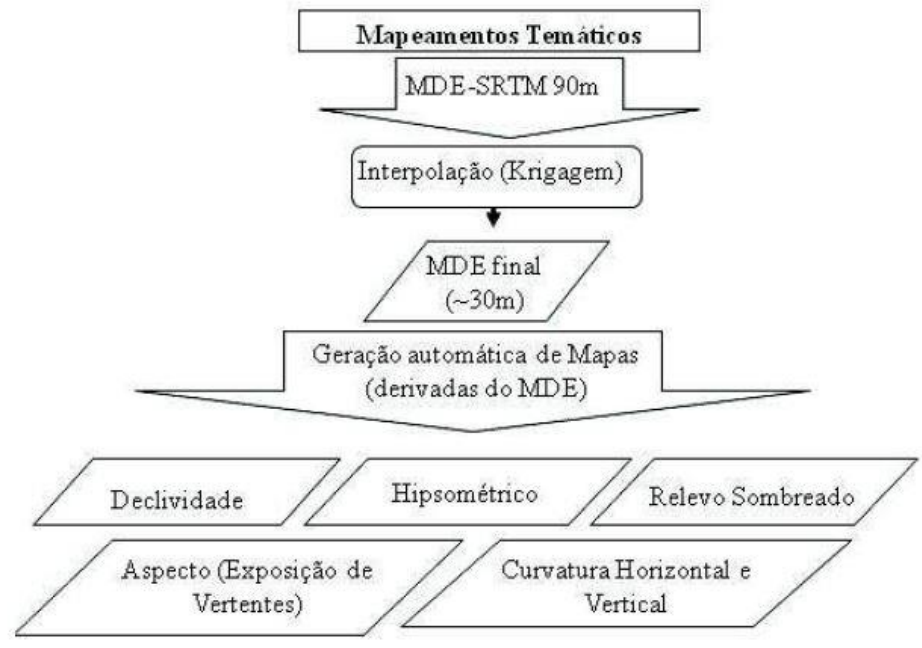

Fonte: Adaptado de Oliveira (2010)

Nesse contexto, os estudos geomorfológicos servem de aporte para o estudo da desertificação, entendido como a degradação da terra nas regiões áridas, semiáridas e sub-úmidas secas, como resultado de vários elementos como as variações climáticas e atividades humanas.

Sobremaneira o mapeamento geomorfológico pode ser tratado como um importante instrumento para identificação e mensuração de áreas que são susceptíveis ou vulneráveis aos processos de desertificação, considerando que algumas feições de relevo possuem um grau de fragilidade elevado que contribui para a ocorrência desse processo.

O processo de desertificação é dinâmico, inerente às interações de elementos da natureza e antrópicos, causando a redução da biodiversidade, diminuição na produção agrícola, através da degradação da terra, dos recursos hídricos, da vegetação e consequente redução da qualidade de vida da população afetada (LIMA et. al., 2012). Está relacionado com a fragilidade do ambiente que ocorre naturalmente, bem como está associada ao uso e ocupação do solo de maneira incorreta. Tal processo apresenta um grau de complexidade considerável, bem como consequências nos âmbitos econômicos, sociais, políticos, culturais e ambientais, necessitando de estudos que abordem a perspectiva sistêmica (SANTOS, 2015).

De acordo com Santos (2015, p. 30), a desertificação constitui-se um tipo de degradação ambiental, que está relacionada a um fenômeno espacial oriundo de desequilíbrio natural, sendo ocasionado pelo uso e ocupação inadequado dos solos.

Por fim, pode-se elencar resumidamente alguns estudos que tratam das temáticas elucidadas anteriormente, especialmente os estudos sobre desertificação. Os estudos em tela abrangem pesquisas recentes e compreendem investigações acadêmicas no nordeste brasileiro, conforme a listagem abaixo, apresentada por Silva (2016):

1. Estudo da degradação/desertificação no núcleo de São Raimundo Nonato - Piauí 
No estudo apresentado Aquino (2010) realizou a análise dos riscos de degradação/desertificação levando em consideração os seguintes parâmetros: a) IC - índice climático, referente aos meses úmidos e meses secos; b) $\mathrm{R}$ - erosividade da chuva; c) $\mathrm{K}$ erodibilidade dos solos; D - declividade das vertentes e e) Índice de Vegetação por Diferença Normalizada (NDVI). Ao elencar esses parâmetros a autora realiza a sobreposição dos mapas com elementos do meio físico: Geologia, Geomorfologia e Altimetria, a autora delimitou as classes de risco de degradação, bem como as unidades geoambientais e suas devidas porcentagens a seguir: i) Superfície Conservada Sedimentar (68,9 \%); ii) Superfície Conservada Cristalina (87,7\%), iii) Superfície Pediplanada (81,5\%); iv) Planície Fluvial $(44,1 \%)$ e por fim v) Vales Pedimentados/Interplanálticos $(2,4 \%)$.

2. Mapeamento das unidades geoambientais e estudo do risco de degradação/desertificação nos municípios de Castelo do Piauí e Juazeiro do Piauí.

Santos (2015) analizou os riscos de degradação e desertificação nos municípios de Castelo do Piauí e Juazeiro do Piauí, apresentando as seguintes unidades geoambientais: a) Superfície Pedimentada Dissecada em Morros/Colinas e Formas Tabulares de Castelo do Piauí; b) Patamares Estruturais da Bacia do Rio Poti, c) Superfície Pedimentada Dissecada em Morros/Colinas e Formas Tabulares de Juazeiro do Piauí, d) Rebordos Cuestiformes Conservados do Interior da Bacia Sedimentar do Maranhão/Piauí e e)Vale da Bacia do Rio Poti. Assim como Aquino (2010), Santos (2015) fundamenta-se nos seguintes elementos: NDVI, severidade climática, erosividade, declividade e erodibilidade.

3. Mapeamento Geomorfológico como subsídio ao estudo da desertificação no norte da Bahia.

Lima et. al. (2011), propôs como objetivo do estudo a elaboração de um mapa geomorfológico da região norte da Bahia, como forma de relacionar a morfologia do relevo e a incidência dos processos de desertificação. Os autores utilizam como aporte teórico a taxonomia de relevo proposta por Ross (1992). Em detrimento disto, analisam as áreas com grau de erosividade considerável e que representam instabilidade ambiental como insumo para identificação das áreas susceptíveis à desertificação (ASD).

4. Mapeamento e Caracterização Geomorfológica: Ecorregião Raso da Catarina e Entorno NE da Bahia.

Oliveira e Chaves (2010), trataram a Ecorregião Raso da Catarina-BA como área de estudo, objetivaram a elaboração de mapeamento geomorfológico, bem como a caracterização morfológica da área, a partir de metodologias amplamente divulgadas, como as propostas por Ross em 1990 e 1992 e com o uso das geotecnologias: Sistemas de Informações Geográficas e Sensoriamento Remoto. Para execução do mapeamento foi utilizado pelos autores o Modelo Digital de Elevação, 
obtido pelo programa Shuttle Radar Topography Mission da Nasa, contendo resolução espacial de 90 m. A partir do MDE, permite-se a geração de subprodutos como: os mapas de declividade, mapas hipsométricos e os mapas de relevo sombreado.

5. Degradação Ambiental e Desertificação no Nordeste Brasileiro: o contexto da bacia hidrográfica do rio Acaraú - Ceará

No presente estudo Nascimento (2006) realizou uma análise geral da problemática da desertificação nas escalas mundial, regional e local, tratando a bacia hidrográfica do rio Acaraú como uma unidade de gestão e planejamento territorial, no que tange a degradação ambiental e o processo de desertificação. Nesse contexto, Nascimento (2006), faz o levantamento do diagnóstico socioambiental com base no aporte teórico-metodológico da análise geoambiental integrada. Em relação à área de estudo, apresenta um desenvolvimento econômico irrisório que, de acordo com o autor, corrobora para a debilitação da sustentabilidade ambiental, bem como a vulnerabilidade ambiental ocasionada pela desertificação.

\section{CONSIDERAÇÕES FINAIS}

Em termos gerais a Geomorfologia demonstra-se como uma ciência importante para os estudos ambientais, no cerne das abordagens teórico-metodológicas, empregadas pelos pesquisadores para a execução de seus respectivos estudos. Nesse contexto as propostas metodológicas propostas por ROSS (1992), Projeto RADAMBRASIL (1982), AB'SABER (1969) e IBGE (2009), demonstram importantes recursos para análise do relevo em termos de escala local e regional, a partir da compartimentação do relevo, divisão taxônomica e hierarquização das unidades de relevo.

Nesse contexto, nota-se a importância do mapeamento geomorfológico relacionado aos estudos ambientais, torna-se importante ferramenta para análise e síntese dos processos dinâmicos que envolvem os sistemas ambientais (ROSS, 2006), no que tange a identificação, caracterização e espacialização das unidades de relevo, com objetivo de geração de produtos cartográficos para subsidiar as pesquisas.

Aliado às bases teórico-metodológicas da Geomorfologia há uma ampliação do uso das geotecnologias no auxílio dos mapeamentos geomorfológicos, seja por técnicas de sensoriamento remoto ou pelo uso dos Sistemas de Informação Geográficas (SIGs), aquisição de dados geoespaciais, elaboração dos Modelos Digitais do Terreno (MDTs) e a geração de seus subprodutos: Declividade, Relevo Sombreado e Mapas Hipsométricos, que permitem uma análise detalhada do relevo. No que tange a aplicação dos SIGs nos estudos ambientais, os levantamentos 
sobre áreas susceptíveis à desertificação (ASD), ou simplesmente, os estudos sobre desertificação e/ou degradação ambiental, constituem uma base de grandes possibilidades para uma complementação mais sólida dos levantamentos, baseados em metodologias já consolidadas pelos pesquisadores, assim como, o avanço das técnicas de mapeamento geomorfológico.

\section{REFERÊNCIAS}

AB'SABER, A. N. Um conceito de Geomorfologia a serviço das pesquisas sobre o Quaternário. In: Geomorfologia. n.18. São Paulo: IGEOG/USP. 1969.

AUGUSTIN, C.H.R.R. et. al. Mapeamento geomorfológico da Serra do Espinhaço Meridional: primeira aproximação. Revista Geonomomos. V. 2, n. 19, p. 50-69, dez. 2011.

AQUINO, C. M. S. Estudo da degradação/desertificação no núcleo de São Raimundo Nonato Piauí. Tese (Doutorado em Geografia). Universidade Federal de Sergipe (UFSE). São Cristovão, 2010.

CASSETI, V.: $\quad$ Geomorfologia. 2006. Disponível em: < http://www.funape.org.br/geomorfologia/cap1/index.php >. Acesso em: 27 mai. 2016.

CHRISTOFOLETTI, A. Modelagem de sistemas ambientais. 1. ed. São Paulo: Edgard Blucher, 1999.

FLORENZANO, T. G. (org)., Geomorfologia: conceitos e tecnologias atuais. Oficina de Textos, São Paulo. 2008.

INSTITUTO BRASILEIRO DE GEOGRAFIA E ESTATÍSTICA - IBGE. Manual técnico de Geomorfologia. Coordenação de Recursos Naturais e Estudos Ambientais. 2. ed. Rio de Janeiro, 2009.

LIMA, G. M.; et. al. Mapeamento Geomorfológico como subsídio ao estudo da desertificação no norte da Bahia. Revista Geonorte, Manaus, v. 2, n. 4, p.588-598, jun. 2012.

NASCIMENTO, F. R. do. Degradação Ambiental e Desertificação no Nordeste Brasileiro: o contexto da bacia hidrográfica do rio Acaraú - Ceará. 2006. 340 f. Tese (Doutorado) - Programa de Pós-graduação em Geografia, Universidade Federal Fluminense, Niterói, 2006.

OLIVEIRA, J. H. M., CHAVES, J. M. Mapeamento e caracterização geomorfológica: Ecorregião Raso da Catarina e Entorno NE da Bahia. Mercator - Vol. 9, № 20, 2010: Set./Dez.

ROCHA, V. da. Utilização do Geoprocessamento para simular reconstituição do relevo após atividades de mineração. Instituto de Geociências. UFMG. Belo Horizonte. 2011.

ROSS, Jurandyr L. Sanches. Geografia do Brasil. 1. ed. São Paulo: EDUSP, 1996.

Ecogeografia do Brasil: subsídios para o planejamento ambiental. São Paulo: Oficina de Textos, 2006. 
SANTOS, F. A. Mapeamento das unidades geoambientais e estudo do risco de degradação/desertificação nos municípios de Castelo do Piauí e Juazeiro do Piauí. 187 f. Dissertação (Mestrado em Geografia). Universidade Federal do Piauí, Teresina, 2015.

SCHINEIDER, V. Mapeamento geomorfológico e zoneamento ambiental de fragilidades na bacia hidrográfica do Rio Barra Seca - Espírito Santo. Universidade Federal do Espírito Santo. 2011.

SILVA, F. J. Compartimentação geomorfológica e estudo integrado dos estudos ambientais: referências teórico-metodológicas e panorama das pesquisas no nordeste brasileiro. Monografia (Departamento de Geografia). Universidade Federal do Piauí, Teresina, 2016.

SILVA, T. M. Mapeamentos Geomorfológicos: Escalas, aplicações e técnicas de compartimentação do relevo. GeoUERJ, [s.1.], v. 1, n. 17, p.70-94, jun. 2007. Universidade de Estado do Rio de Janeiro.

\section{AGRADECIMENTOS}

Os agradecimentos vão para o colega e Professor Henrique pelas suas contribuições e observações detalhadas para a escrita do artigo e também ao amigo e colega de graduação na UFPI, Francisco John Lennon pelas contribuições pertinentes e assessoria para a organização do presente artigo.

Recebido em: 14/08/2016

Aceito para publicação em: 01/10/2016 